Journal of Bangladesh Academy of Sciences, Vol. 35, No. 2, 221-228, 2011

\title{
STUDIES ON THE ELECTRICAL PROPERTIES OF Cu SUBSTITUTED Li-FERRITES
}

\author{
M. SAMIR ULLAH ${ }^{*}$, S. MANJURA HOQUE ${ }^{2}$, F.A. KHAN ${ }^{1}$, SAROAUT NOOR $^{3}$, \\ M.A. HAKIM ${ }^{2}$ AND D.K. SAHA ${ }^{2}$ \\ Department of Physics, Bangladesh University of Engineering and Technology, \\ Dhaka-1000, Bangladesh
}

\section{ABSTRACT}

Polycrystalline $\mathrm{Li}-\mathrm{Cu}$ mixed ferrites were prepared by double sintering ceramic technique. $\mathrm{Cu}$ substituted $\mathrm{Li}$ ferrites having the general formula $\mathrm{Li}_{0.5-\mathrm{x} / 2} \mathrm{Cu}_{\mathrm{x}} \mathrm{Fe}_{2.5-\mathrm{x} / 2} \mathrm{O}_{4}$ where, $\mathrm{x}=0.0$ to 1.0 and the samples were sintered at $1100^{\circ} \mathrm{C}$ for 3 hours in the normal atmosphere. The prepared samples were confirmed in the spinel structure by the X-ray diffraction method. The lattice parameter and porosity were calculated for different compositions. The electrical resistivity and dielectric constant have been investigated as a function of composition and temperature. It was observed that the resistivity decreased with increasing temperature and exhibited semiconducting nature of the sample. The compositional variation of resistivity and dielectric constant showed inversed trend with each other at room temperature for $\mathrm{Cu}$ content, $\mathrm{x}>0.3$. This was found to support the electron hopping conduction mechanism. The dielectric constant increased slowly with temperature in the beginning and after that dielectric constant increased rapidly for different samples. As the temperature increased, thermal energy provided to the sample played an important role to decrease the relaxation time and hence there was an increase in dielectric constant. Dielectric constant has been observed as a function of frequency and it decreased with increasing frequency.

Key words: Electrical resistivity, Porosity, Dielectric constant, Electron hopping

\section{INTRODUCTION}

The field of ferrites is very important for scientists, researchers and engineers due to their various potential applications and interesting physics involved in it (Pandya et al. 2005). Soft ferrites are used in radio, television, microwave and satellite communication, radars, transformer and magnetic recording (Randhawa et al. 2004, Hoque et al. 2002, Viswanathan and Murthy 1990). The study of electric and dielectric behaviour carry equal importance, both are dependent on several factors such as the method of preparation and substitution of different ions (Song and Koh 1996, Suryavanshi et al. 2000).

\footnotetext{
"Corresponding author: <samirullah@phy.buet.ac.bd.>.

${ }^{2}$ Materials Science Division, Atomic Energy Center, Dhaka-1000, Bangladesh.

${ }^{3}$ Department of Physics, Khulna University of Engineering and Technology, Khulna-9203.
} 
Lithium ferrite and mixed lithium ferrites have become important materials for microwave applications because of their low costs, high curie temperature and low dielectric losses (Bellad et al. 2000). The modification of the properties of lithium ferrite due to substitution of various ions have been investigated by several researchers. They have studied Li-Ti, Li-Ge and Li-Mg ferrites (Mazen et al. 1993, Yousuf et al. 1999, Ravinder and Reddy 2003). There is a lack of data on $\mathrm{Cu}$ substituted $\mathrm{Li}$-ferrite. In the present study, a series of $\mathrm{Li}_{0.5-}$ ${ }_{x / 2} \mathrm{Cu}_{\mathrm{x}} \mathrm{Fe}_{2.5-\mathrm{x} / 2} \mathrm{O}_{4}$ were prepared using the solid state reaction method and investigation of $\mathrm{Cu}$ substituted $\mathrm{Li}$ ferrite to understand its electrical properties.

\section{MATERIALS AND METHODS}

$\mathrm{Li}_{0.5-\mathrm{x} / 2} \mathrm{Cu}_{\mathrm{x}} \mathrm{Fe}_{2.5-\mathrm{x} / 2} \mathrm{O}_{4}$ (where $\mathrm{x}=0.0$ to 1.0 ) samples have been prepared by using conventional ceramic technique. $\mathrm{Li}_{2} \mathrm{CO}_{3}, \mathrm{CuO}$ and $\mathrm{Fe}_{2} \mathrm{O}_{3}$ of high purity were mixed homogeneously having appropriate ratio of cations. The resultant powder was then steel balls milled for 5 hours to produce fine powders of mixed constituents. The samples were dried and the dried powder was pressed into disc shape. The disc shaped samples were pre-fired at $1000^{\circ} \mathrm{C}$ for 3 hours in air to form ferrite through solid state reaction. The raw ferrite was wet milled extensively to get fine powder. The powder was then dried and mixed with polyvinyl alcohol as a binder for granulation. Then the granulated powder was pressed into desired shapes using metal dies. Dies of several shapes were used for pressing. Finally pressed products were sintered at $1100^{\circ} \mathrm{C}$ in air for 3 hours. Formation of ferrite was confirmed by Philips analytical X-ray diffractometer using $\mathrm{CuK}_{\alpha}$ radiation. Crystal structure was determined from XRD data. The measurement of the electrical resistivity was carried out over temperature range $300-500 \mathrm{~K}$. The variation of dielectric constant with temperature was measured from room temperature to $500 \mathrm{~K}$. Frequency dependence of dielectric constant was measured in the range of $10 \mathrm{kHz}-500 \mathrm{kHz}$ with LCR meter by two probe methods.

\section{RESULTS AND DISCUSSION}

The XRD patterns are shown in Fig. 1 for $\mathrm{Li}_{0.5-\mathrm{x} / 2} \mathrm{Cu}_{\mathrm{x}} \mathrm{Fe}_{2.5-\mathrm{x} / 2} \mathrm{O}_{4}$ ferrites sintered at $1100^{\circ} \mathrm{C}$ and it can be seen that the samples confirmed the formation of cubic spinel structure. In order to find the lattice parameter for different samples, Nelson-Riley (N-R) extrapolation function $\mathrm{F}(\theta)$ is used (Nelson and Riley 1945, Cullity 1959) and presented in Fig. 2.

It is observed that the lattice parameter increases with the increase of $\mathrm{Cu}$ content. This is due to fact that the replacement of $\mathrm{Fe}^{3+}\left(0.64^{\prime}\right)$ and $\mathrm{Li}^{+}\left(0.688^{\prime}\right)$ by $\mathrm{Cu}^{2+}(0.72$ ') ion (Mazen and Dawoud 1999). It does not follow Vegards law (Denton and Ashcroft 1991) properly, because of the structural change at higher $\mathrm{Cu}$ content. The porosity of the samples were calculated from both X-ray and bulk densities and as shown in Fig. 3. It can be observed that porosity is decreased with increase of $\mathrm{Cu}$ content which provides more densification for the samples containing higher $\mathrm{Cu}$ content. 
Fig. 4 shows the variation of the electrical resistivity, $\ln \rho$ with $(1 / \mathrm{T}) \times 1000$ for the investigated of $\mathrm{Li}_{0.5-\mathrm{x} / 2} \mathrm{Cu}_{\mathrm{x}} \mathrm{Fe}_{2.5-\mathrm{x} / 2} \mathrm{O}_{4}$ samples sintered at $1100^{\circ} \mathrm{C}$. It is obvious that the electrical resistivity decreases with increasing temperatures and exhibits semiconducting behaviour. The values of electrical resistivity, $\rho$ lies between $10^{3}$ and $10^{4}$ at room temperature and are presented in Fig. 5. This indicates that they can be used as insulator at room temperature. The highest value of $\rho$ is obtained for $\mathrm{x}=0.3$ and for $\mathrm{x}>0.3$, resistivity decreases with the increase of $\mathrm{Cu}$ in the composition. When significant amount of $\mathrm{Cu}^{2+}$ ions content, $\mathrm{x}$, is increased, then chance of formation of $\mathrm{Fe}^{2+}$ ions maximizes. So the probability of hopping between $\mathrm{Fe}^{2+}$ and $\mathrm{Fe}^{3+}$ increases after that $\mathrm{x}=0.3$ and hence the resistivity decreases for $\mathrm{x}>0.3$. This can be explained by qualitative IR analysis (Mazen 2000), introducing of the divalent $\mathrm{Cu}^{+2}$ ions, at room temperature, the resistivity increases up to $\mathrm{x}=0.3$, but it decreases for $\mathrm{x}>0.3$, which can be attributed to the decrease of $\mathrm{Fe}^{3+}$ and $\mathrm{Li}^{+}$concentration with increase of $\mathrm{Cu}$ content, but $\mathrm{Fe}^{2+}$ ions are increased. This indicates that $\mathrm{Fe}^{+2}$ ions are present as traces in the samples of $\mathrm{x}>0.3$. Fig. 6 shows that the variation of dielectric constant with $\mathrm{Cu}$ content is of inverse trend compared to that of the electrical resistivity versus $\mathrm{Cu}$ content for $\mathrm{x}>0.3$. This is a confirmation of the correlation between electrical resistivity and dielectric constant. This trend is similar for other Li-based ferrites (Radha and Ravinder 1995).
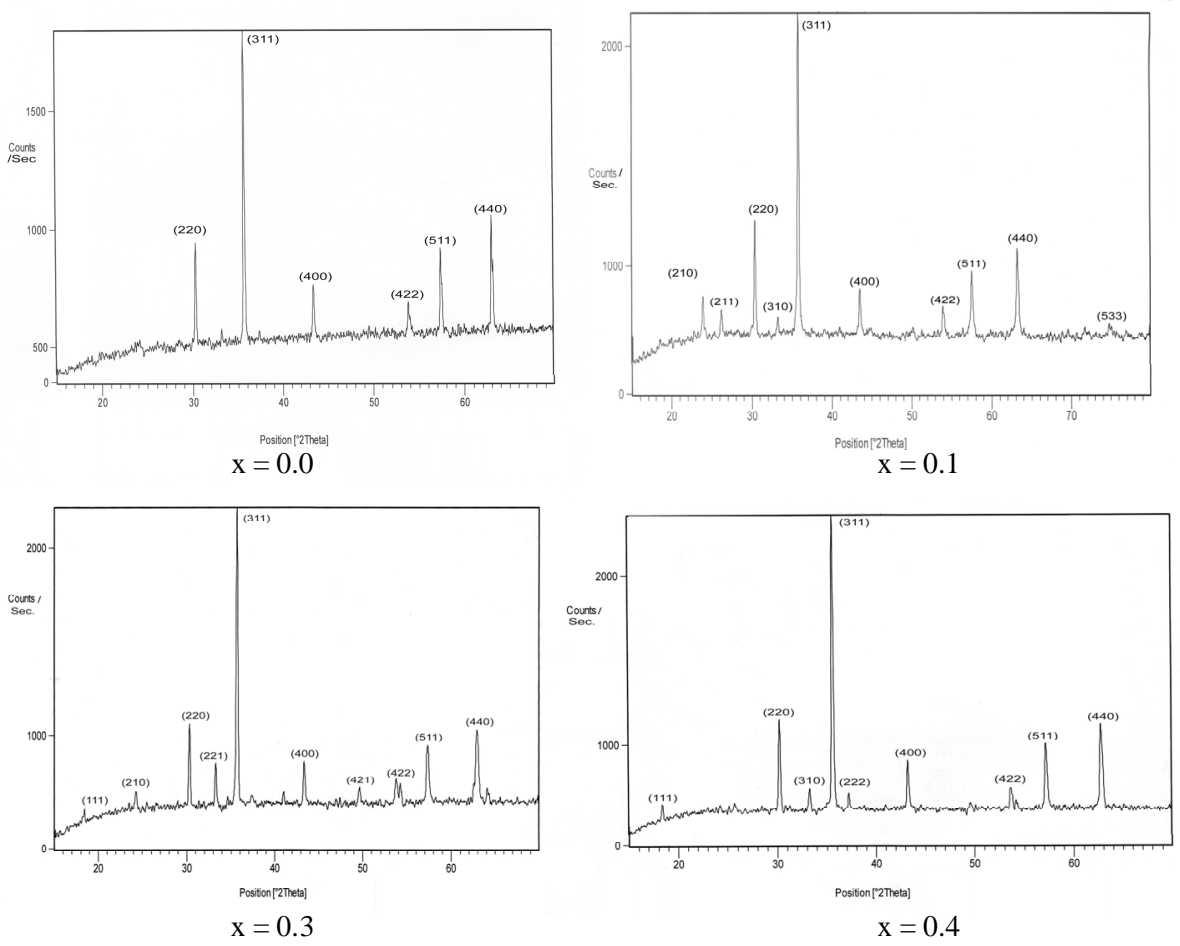

(Contd.) 

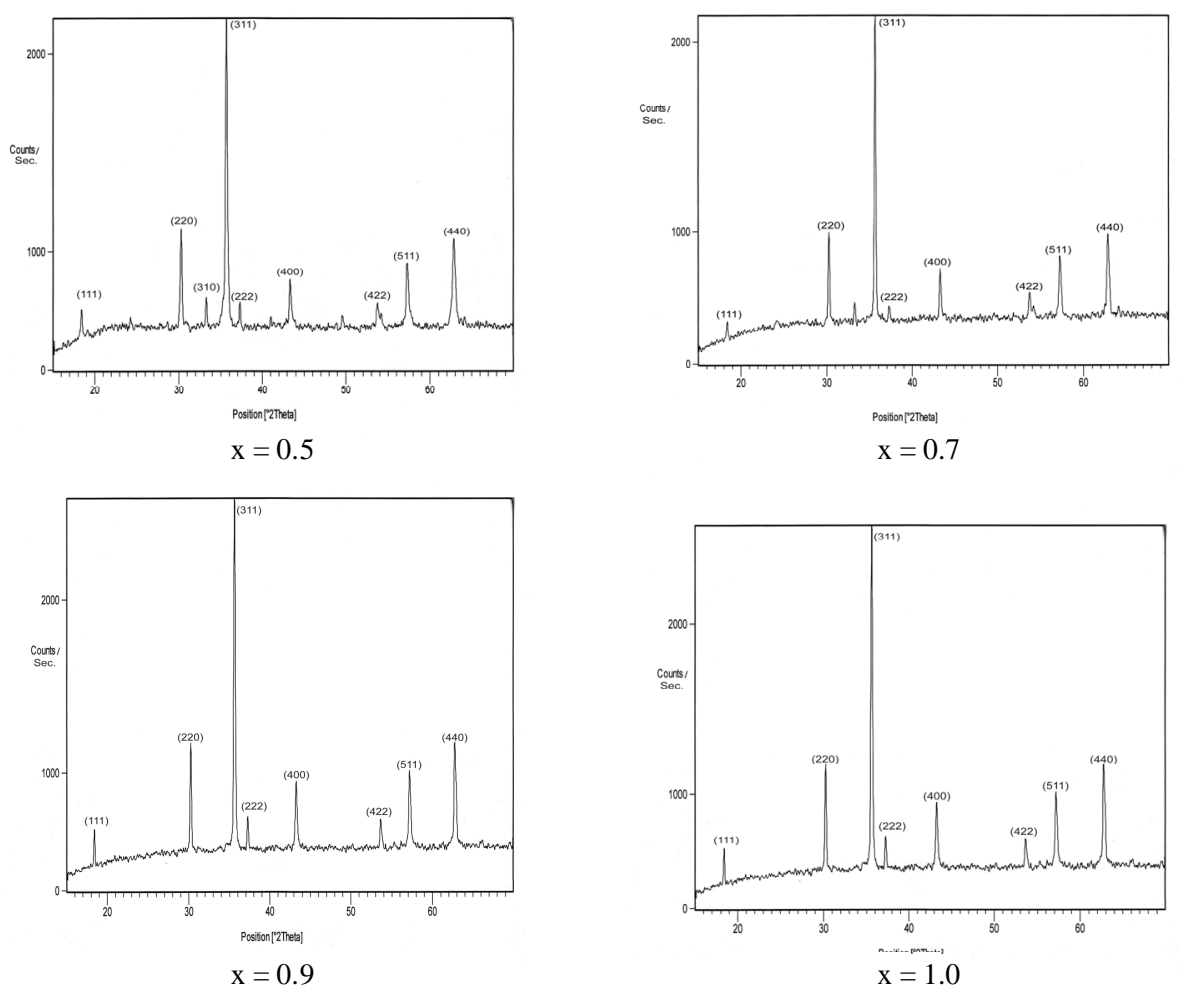

Fig. 1. X-ray diffraction pattern of $\mathrm{Li}_{0.5-\mathrm{x} / 2} \mathrm{Cu}_{\mathrm{x}} \mathrm{Fe}_{2.5-\mathrm{x} / 2} \mathrm{O}_{4}$ sintered at $1100^{\circ} \mathrm{C}$.

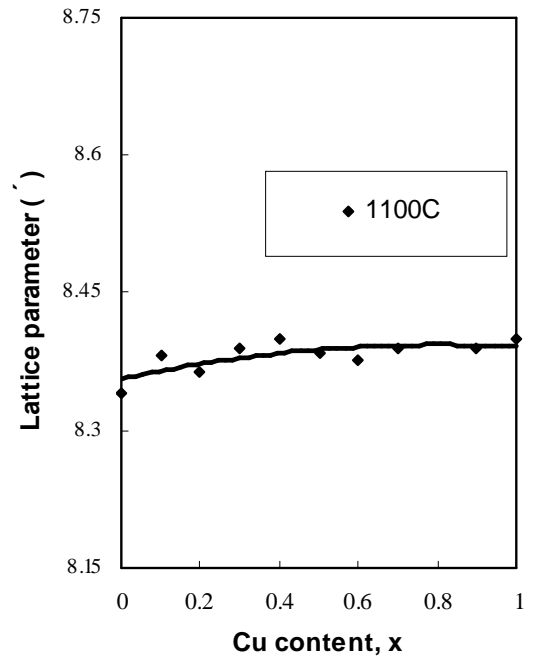

Fig. 2. Variation of lattice parameter with $\mathrm{Cu}$ content, sintered at $1100^{\circ} \mathrm{C}$.

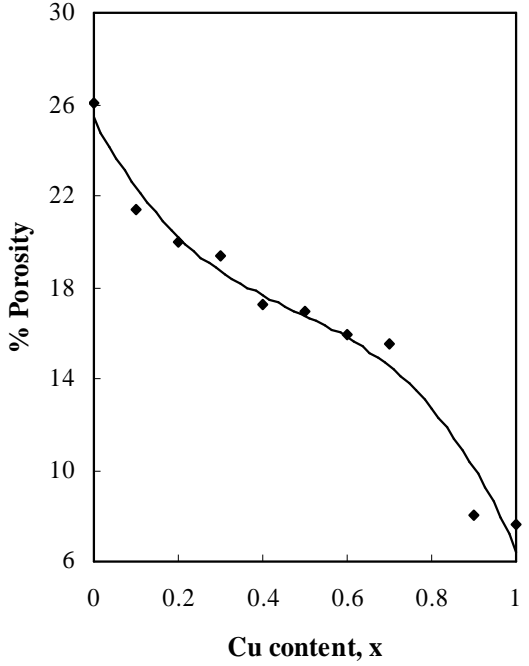

Fig. 3.Variation of $\%$ porosity with $\mathrm{Cu}$ content, sintered at $1100^{\circ} \mathrm{C}$. 


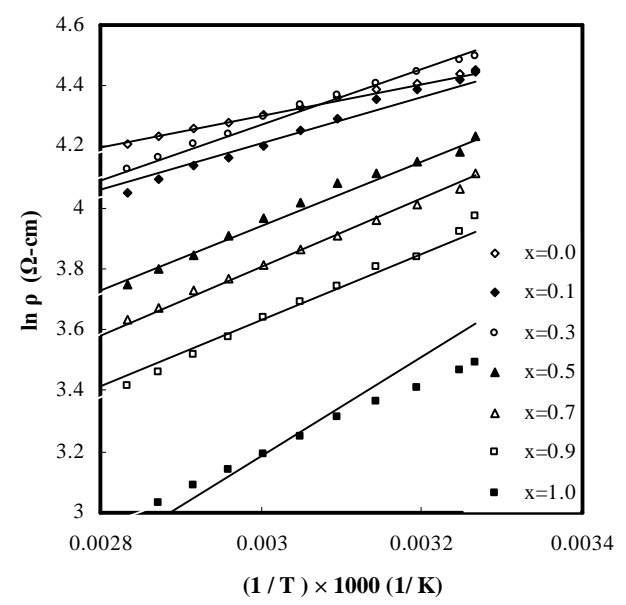

Fig. 4. Variation of $\ln \rho(\Omega-\mathrm{cm})$ with $(1 / \mathrm{T}) \times 1000$ for different $\mathrm{Cu}$ content.

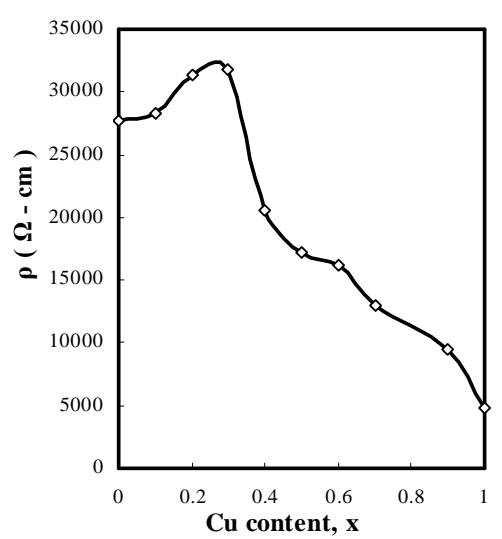

Fig. 5. Variation of electrical resistivity, $\rho$ with $\mathrm{Cu}$ content at room temperature.

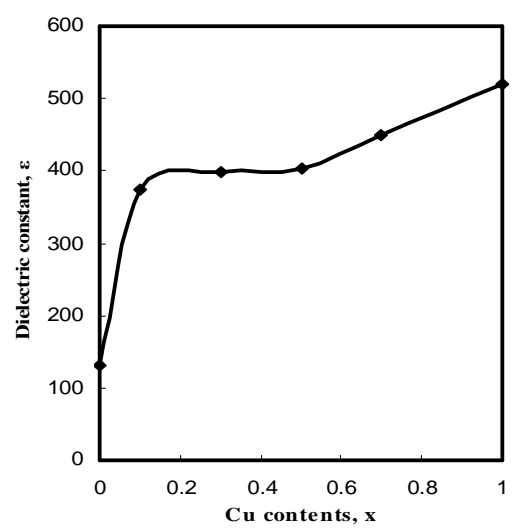

Fig. 6. Variation of dielectric constant, $\varepsilon$ with $\mathrm{Cu}$ content at room temperature.

The temperature variation of dielectric constant, $\varepsilon$ has been studied at $10 \mathrm{kHz}$ and is shown in Fig. 7. It can be seen that the dielectric constant increases slowly with the temperature in the beginning and then increases rapidly and sharply for different samples. The resistivity of ferrites decreases with increase in temperatures. According to Koops (Shaikh et al. 1999) the dielectric constant is inversely proportional to the square root of resistivity. Therefore, the increase in dielectric constant with temperature is expected. The dielectric constant of ferrites is attributed to the four types of polarization, viz., interfacial, dipolar, ionic and electronic polarization (Maisnam et al. 2008). Interfacial polarization increases with the increase of temperature while the dipolar polarization decreases with the increase of temperature. The observed temperature dependence of dielectric constant can be explained with the help of relaxation time in Debye's equation 
(Hench and West 1990, Moulson and Herbert 1990) and is given by $\tau=\tau_{\mathrm{o}} \exp \left(\mathrm{E}_{\mathrm{a}} / \mathrm{kT}\right.$ ), where $E_{a}$ is the value of activation energy and $k$ is the Boltzmann constant. According to this equation, dielectric constant and relaxation time are of inverse relation with each other. At low temperature, the value of relaxation time is high and hence dielectric constant is low. When the temperature is increased, thermal energy provided to the sample plays a role of decreasing the relaxation time and hence there is an increase in dielectric constant.

The variation of dielectric constant with frequency in the range of 10 to $500 \mathrm{kHz}$ at room temperature is shown in Fig. 8. This behavior of a dielectric may be explained qualitatively by the fact that the mechanism of the polarization process in ferrite is similar to that of the conduction process. The electron hopping $\left(\mathrm{Fe}^{2+} \leftrightarrow \mathrm{Fe}^{3+}\right.$ or $\left.\mathrm{Cu}^{2+} \leftrightarrow \mathrm{Cu}^{+}\right)$ occurs by electron transfer between adjacent octahedral sites (B-sites) in the spinel lattice. Thus by the electronic exchange : $\mathrm{Fe}^{2+}+\mathrm{Cu}^{2+} \leftrightarrow \mathrm{Fe}^{3+}+\mathrm{Cu}^{+}$, one obtains local displacements of electrons in the direction of the applied field, these displacements determine the polarization of the ferrite. It is known that the effect of polarization is to reduce the field inside the medium. Hence, the dielectric constant is decreased as the frequency is increased.

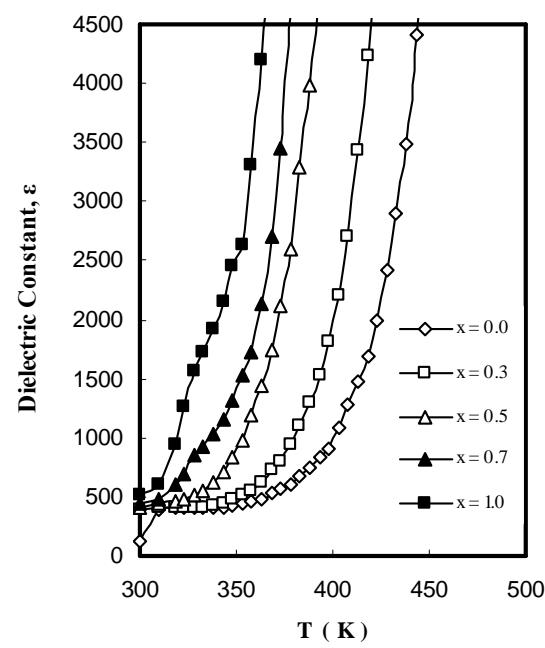

Fig. 7. Variation of dielectric constant, $\varepsilon$ with temperatures at $10 \mathrm{kHz}$.

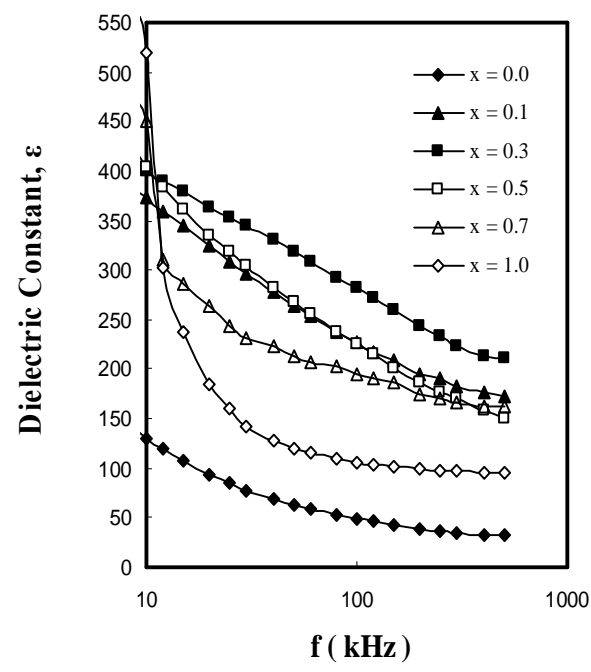

Fig. 8. Variation of dielectric constant, $\varepsilon$ with frequency at room temperature.

\section{CONCLUSIONS}

The XRD pattern confirms that samples exhibit the spinel structure. The temperature dependence of electrical resistivity illustrates that all samples are semiconducting in 
nature. The electrical resistivity showed a fall with substitution of $\mathrm{Cu}$ but the dielectric constant increased with progressive substitution of $\mathrm{Cu}$. Dielectric constant increased with the increase of temperature which indicated that interfacial polarization plays an important role in this temperature range. The decrease in dielectric constant with increase in frequency is due to the fact that the electronic exchange between $\mathrm{Fe}^{2+}$ and $\mathrm{Fe}^{3+}$ ions does not flow the frequency of the applied ac field.

\section{ACKNOWLEDGMENTS}

Authors acknowledge to the Department of Physics, Bangladesh University of Engineering and Technology (BUET), Dhaka and Materials Science Division, Atomic Energy Center Dhaka, for providing support to carry out of this work.

\section{REFERENCES}

Bellad, S. S., C.S.Watawe, M. A. Shaikh, and K. B. Chougule. 2000. Cadmium substituted high permeability lithium ferrite. Ind. Acd. Sci. Bull. Mater. Sci. 23(2): 83-85.

Cullity, D. B. 1959. Elements of X-ray Diffraction. Addison-Wesley Publishing Company, Inc., Massachusetts; Second Printing.

Denton, R. A. and W. N. Ashcroft. 1991. Vegard's law. Phys. Rev. A 43: 3161.

Hench, L.L. and J. K. West. 1990. Principle of Electronic Ceramics. Wiley, New York, pp. 185.

Hoque, M.S., A.M. Choudhury and F.M. Islam. 2002. Characterization of Ni-Cu mixed spinel ferrite. J. Magn. Magn. Mater. 251: 292-303.

Maisnam, M., S. Phanjoubam, K. N. H. Sarma, P. O. Thakur, L. Radhapiyari Devi and Prakash Chandra. 2008. Influence of temperature on the dielectric behaviour of $\mathrm{Co}^{2+}$ substituted $\mathrm{Li}-\mathrm{Ni}$ Mn ferrites. Ind. J. Engg. Mat. Sci. 15: 199-202.

Mazen, A. S and A. H. Dawoud. 1999. Structure and Magnetic Properties of Li-Cu Ferrite. Phys. Stat. Sol. (a) 172: 275-289.

Mazen, A. S. 2000. Infrared absorption and dielectric properties of $\mathrm{Li}-\mathrm{Cu}$ ferrite. Mater, Chem. Phys. 62: 139-147.

Mazen, A. S., H. M. Abdullah, I. R. Nakhla, F. Metawe and M. H. Zaki. 1993. X-ray analysis and IR absorption spectra of Li-Ge ferrite. Mater. Chem. Phys. 34: 35-40.

Moulson, A. J. and J. M. Herbert. 1990. Electro ceramics: Materials, properties, applications. Chapman and Hall, pp. 52.

Nelson, B. J. and P. D. Riley. 1945. An experimental investigation of extrapolation methods in the derivation of accurate unit-cell dimensions of crystals. Proc. Phys. Soc. London 57: 160.

Pandya, P. M., B. K. Modi and H.H. Joshi. 2005. Study of conduction mechanism in aluminium and magnesium co-substituted lithium ferrite. J. Mat. Sci. 40: 5223-5232.

Radha, K. and D. Ravinder. 1995. Frequency and composition dependence of dielectric behaviour of mixed Li-Cd ferrites. Ind. J. Pure \& Appl. Phys. 33: 74-77.

Randhawa, S.B., J. K. Sweety, Kaur Manpreet and M. J. Greneche. 2004. Synthesis of ferrites: Thermal analysis of some transition metal tris (maleato) ferrates (III). J. Therm. Anal. Calo. 75: 101-111.

Ravinder, D. and B. V. P. Reddy. 2003. Thermoelectric power studies of polycrystalline magnesium substituted lithium ferrites. J. Magn. Magn. Mater. 263: 127-133. 
Shaikh, M. A., S. S. Bellad and K. B. Chougule. 1999. Temperature and frequency dependent dielectric properties of $\mathrm{Zn}$ substituted Li-Mg ferrites. J. Magn. Magn. Mater. 195: 384-390.

Song, J. M. and G. J. Koh. 1996. Studies of polycrystalline Cobalt Substituted Lithium Ferrites. IEEE Trans. Mag. 32(2): 411-415.

Suryavanshi, S. S., M. S. Kabbur, B.U. Deshmukh and R. S. Sawant. 2000. Complex Permeability Studies of Li ${ }^{1+}$ Substituted Cu-Zn Ferrites. J. Elec. Mat. 29(7): 979-983.

Viswanathan, B. and K. R.V. Murthy. 1990. Ferrite Materials. Springer-Verlag, Berlin.

Yousif, A. A., E. Elazain, A. S. Mazen, H. H. Sutherland, H. M. Abdullah and S. F. Mansour. 1994. A Mossbauer and X-ray diffraction investigation of Li-Ti ferrites. J. Phys. Condensed Matter. 6: $5717-5721$.

(Received revised manuscript on 15 September, 2011) 